\title{
Atatürk Üniversitesi Ziraat Fakültesi Ziraat İșletme ve Döner Sermaye Müdürlüğü Uygulama Çiftliğinde Bulunan Bazı Hayvan Barınaklarının Yapısal Özellikleri Üzerine Bir Araştırma
}

\begin{tabular}{l|c}
\hline $\begin{array}{l}\text { Araştırma /Research } \\
\text { Geliş Tarihi /Received } \\
\text { 02.05.2017 }\end{array}$ & Recep YANIK*, Mustafa OKUROĞLU \\
$\begin{array}{l}\text { Kabul Tarih /Accepted } \\
\text { 15.09.2017 }\end{array}$ & Atatürk Üniversitesi, Ziraat Fakültesi Tarımsal Yapılar ve Sulama Bölümü, \\
DOI & Erzurum- Türkiye \\
$\begin{array}{l}\text { 10.28955/alinterizbd.310120 } \\
\text { ISSN 2564-7814 }\end{array}$ & *e-posta: recep.yanik@atauni.edu.tr \\
e-ISSN 2587-2249 & \\
\hline
\end{tabular}

Öz: Bu çalışma; Atatürk Üniversitesi Ziraat Fakültesi Ziraat İşletme ve Döner Sermeye Müdürlüğü Uygulama Çiftliğinde bulunan hayvan barınaklarının yapısal özelliklerinin incelenmesi amacıyla yapılmıștır. Hayvan barınaklarının yapısal durumları yerinde ölçümler yapılmak suretiyle belirlenmiş ve planlama yönünden eksik ve hatalı durumlar ortaya konmuştur. Barınaklar genel olarak hayvanlar için uygun planlama kriterlerini taşımalarına karşın, barınaklarda bazı yapı elemanlarının boyutları istenen değerlerden daha küçük bazıları ise gereğinden büyük planlanmıştır.

Anahtar Kelimeler: Barınak, hayvan barınakları, ahır, kümes

\section{A Research on Structural Properties of Some Animal Barns in Agricultural Managing and Revolving Fund Application Farm of Atatürk University Agriculture Faculty}

\begin{abstract}
This study has been aimed to invastigate the structural properties of animal barns of agricultural managing and revolving fund application farm of Atatürk University Agriculture Faculty. In this study;animal barns, as cattle barns and poultry house were incastigated, structural conditions of these buildings were determined by measuring in situ. Lack and wrong conditions in these buildings were introduced. Although barns generally have appropriate planning criteria for animals, the dimensions of some building elements in the barn are smaller than the required values and some are planned to be larger than necessary.
\end{abstract}

Keywords: Barn, animal barns, cattle barn, poultry house,

\section{GİRIs}

Tarımsal işletmelerde hayvan barınakları, işletmedeki en önemli yapılardır. Hayvancılık; fazla bakım ve özene gereksinme gösterdiğinden, çiftçi zamanının çoğunu barınaklarda geçirir. Bu nedenle; hayvan barınakları planlanırken, hayvanların özel istekleri yanında hayvancılıkla uğraşan insanların da gereksinimleri daima göz önüne alınmalıdır (Balaban ve Şen 1988).

Hayvan barınakları; hayvanlar ve bakıcılar için sağlıklı ve konforlu bir çevrenin oluşturulmasına, gerekli işgücünün rasyonel olacak şekilde organize edilmesine, yetiştiriciliğin ekonomik olmasına, insan sağlığı ve çevre kirliliği ile ilgili kurallara uygun üretim sağlanmasına olanak verecek şekilde planlanmalıdır (Olgun 2011).

Ekmekyapar (1999)'a göre tarım işletmelerinde hayvan barınaklarının planlanmasında göz önünde bulundurulması gerekli noktalar; işletme avlusunun düzenlenme ilkelerine bağlı kalınarak hayvan barınaklarının diğer yapılarla bütünleşmeye olanak verecek şekilde avlu içine yerleştirilmesi, barınakların hayvanların optimum çevre isteklerini karşılaması, iş gücünün verimli kullanılması, üretimin artırılması ve üretimde kalitenin yükseltilmesi, sağlanacak gelirin yapılan giderleri ekonomik olarak karşılayabilmesi olarak sayılabilir.

Ahır, hayvanların barındırıldığı bir yapı ile sağım, süt işleme, yem depolama yeri ve hayvanların gezindiği avludan oluşan bir ünitedir (Tekinel vd 1988). Ahırların, işletme avlusunda bulunan yapılar içinde önemli bir yeri vardır. Özellikle, ana uğraşısı süt sığırcılı̆̆ 
daha büyük bir öneme sahiptir. Ahırlarda barınan hayvanların ve burada çalışan kişilerin sağlığının korunması yüksek nitelikli ürün elde edilip bunların niteliğinin bozulmadan depolanması amacıyla yapılacak tesislere harcanacak giderlerin çok fazla olması, ahır planlanmasında özenli olmayı zorunlu kılmaktadır (Balaban ve Şen 1988).

Yetiştirme amacına bağlı olarak sığır ahırlarını; süt sığırı ahırları ve besi sığırı ahırları olarak iki grup altında incelemek uygun olur.

Süt sığırı ahırları taban alanının düzenleme şekline göre bağlı (duraklı) ahırlar, serbest ahırlar, serbest duraklı ahırlar olmak üzere üç şekilde planlanabilirler (Ekmekyapar 1999). İklim özelliği farklı olan bölgelerde ahır taban alanının düzenlenmesinde, kapalı veya açık ahır şekillerinden birisinin uygulanması olasıdır (Tekinel ve ark., 1988).

Süt sığırı ahırları planlama yönünden fazla özen gerektiren yapılar olup, planlamada; hayvan sağlığının nitelikli ürün için uygun olmasına, sağım ve sütün korunması için sağlık koşullarının yeterli olmasına, yem ve iş ekonomisi sağlayan düzenek ve ekipman içermesine, ahırda çalışanlar için sağlık ve korunma koşullarının sağlanmasına, ahır inşaatının ekonomik olmasına dikkat edilmelidir (Balaban ve Şen 1988).

Besi sığırı ahırları süt sığırı ahırları kadar korunmuş ve pahalı yapılar olmayı gerektirmez. Besi sığırı ahırlarının planlanmasında göz önünde bulundurulacak başlıca nokta hayvanların kışın şiddetli rüzgarlardan, yazın ise aşırı sıcaktan korunmasıdır (Ekmekyapar 1999).

Besi sığırı ahırları tabanını düzenleme şekline göre; grup bölmeli serbest ahırlar, serbest duraklı ahırlar ve 1zgara tabanlı ahırlar olmak üzere üç şekilde planlanırlar. Dördüncü bir sistem ise bazı bölgelerde uygulanan duraklı (bağlı) ahırlardır. Duraklı ahırlar, işçilik giderlerinin fazla olması ve besiye alınan ve sürekli büyüyen hayvanların vücut ölçülerine sabit durak boyutlarının ayak uyduramaması nedeniyle günümüzde pek az uygulanmaktadır (Anonim 1978). Genç hayvanların ve besiye alınan sığırların bağlı tutulması hareket yeteneğini sınırlaması ile birlikte barınağın yapım maliyeti ve işçilik giderlerinin fazla olması pahalı bir barındırmaya neden olmaktadır (Heinrichs et al. 1987).

Kümesler doğal drenaja sahip, güney, güneydoğu veya güneybatıya eğimli, hafif kumlu yerlerde yapılmalı, komşu işletme arazisi ve avlusundan kümese bir akıntı olmamalıdır. Sürekli rüzgârlara açık veya bütünüyle esintisiz çukur yerlerde kümes yapılmamalıdır. Kümes ana yollara çok yakın olmamalı ancak kümesten ana yollara kolaylıkla ulaşabilmelidir. Fazla gürültülü ve tozlu yerlerde kümes kurulmamalıdır. Yangın tehlikesine karşı kümesler diğer yapılardan 30-40m uzakta kurulmalıdır. Tel kafesli kümeslerde kafesler 1-4 sıralı olarak düzenlenebilir. Kafesleri çok sıralı olan kümeslerde birim taban faydalı alanında barındırılacak tavuk sayısı daha fazla olacak, buna karşın kümeslerde bakım ve kontrol işlemleri güç ve zaman alıcı olacaktır (Şişman ve Okuroğlu 1981). Ağıllar da mevcut olmakla birlikte makalede seçilen bazı hayvan barınaklarına yer verilmiştir.

\section{MATERYAL VE YÖNTEM}

Materyal

Araştırma materyali olarak Atatürk Üniversitesi Ziraat Fakültesi Ziraat İşletme ve Döner Sermaye Müdürlüğü Uygulama Çiftliği bünyesinde bulunan hayvan barınakları (ahırlar ve kümes) seçilmiştir.

\section{Yöntem}

Hayvan barınaklarının yapısal özellikleri barınaklar ayrı ayrı dolaşılıp, gerekli ölçümler yapılıp literatür değerleri ile karşılaştırılmak suretiyle belirlenip değerlendirilmiştir. Barınaklarının çeşitli kısımlarını oluşturan yapı elemanlarının boyutları ve yeterlilik durumları planlama yönünden belirlenmiştir.

\section{ARASTIRMA BULGULARI VE TARTISMA}

İşletmede bulunan 169 sığır kapasiteli kapalı, iki sıralı süt sığırı ahırının dıştan dışa uzunluğu 128,25m genişliği ise 10,50m olup, ahır genişliği iki sıralı duraklı ahırlar için uygun bir genişliktir. Nitekim Balaban ve Şen (1988) iki sıralı ahırlar için genişlik değerinin 10,00-12,00 m den fazla olmaması gerektiğini belirtmişlerdir. Ahır uzun cepheleri güney ve kuzey yönlerine bakacak şekilde planlanmıştır.

Ahır uzun ekseni doğrultusunda ayrılan ve uzunlukları 2 adet 15,65m 1 adet 15,70m 4 adet 15,85m 1 adet 15,96m olan 8 bölme yer almaktadır. Her bir bölmede kuzey yoldaki sıraların birinde 11 adet, 

diğer sırada ise 10 adet durak bulunmaktadır. Güney yöndeki 1 durak genişliği boyutundaki kapıdan avluya çıkılmaktadır.

Ahırda uzun tip dikilme platformu düzenlenmiş olup, platform uzunluğu $210 \mathrm{~cm}$ 'dir. Uzun dikilme platformu düzenlenmesi fazla altlık gerektirir ve ahır maliyetini arttırır (Okuroğlu ve Yağanoğlu 1993).

Yemlik yolu uzun duvarlara bitişik olarak yapılmış ve genişlikleri $110 \mathrm{~cm}$ ve $150 \mathrm{~cm}$ olarak planlanmıștır. Ekmekyapar (1999) yemlik yolu genişliğinin 80-100 cm arasında değisşebileceğini belirtmiştir. Her iki yemlik yolu genişliği gereğinden fazla uzun tutulmuş olup ahır maliyetini artırmıştır.

Yemliklerin dış genişliği $70 \mathrm{~cm}$, yemlik yüksekliği yemliğin ön kısmında $25 \mathrm{~cm}$, arka kısmında ise 50 $\mathrm{cm}$ alınmıștır. Yemlik iç genişliği 40 cm'dir. Ekmekyapar (1981) yemlik iç genişliğinin $60-80 \mathrm{~cm}$ olabileceğini belirtmiştir. Yemlik genişliği yetersiz ve dardır. Yemlik derinliği; Okuroğlu ve Yağanoğlu (1993)'nun önerdiği $15 \mathrm{~cm}$ derinlikten farklıdır.

Servis yolu ile dikilme platformları arasında yer alan idrar kanalı $35 \mathrm{~cm}$ genişliğinde ve $15 \mathrm{~cm}$ derinliğinde planlanmıştır. Geçit yolu tarafında üzeri ızgarayla örtülmüştür. Olgun (2011) idrar kanalı genişliğinin $30-50 \mathrm{~cm}$ arasında, derinliğinin ise dikilme platformu tarafinda $25-45 \mathrm{~cm}$ ve servis yolu tarafında $20-40 \mathrm{~cm}$ olması gerektiğini belirtmişlerdir. İdrar kanalının saptanan genişliği yeterli olup, derinlik yetersizdir.

Ahırda servis yolu genişliği 90 cm'dir. Alkan (1973)'a göre soğuk bölgeler için servis yolu genişliği iki sıralı ahırlarda $120 \mathrm{~cm}$ olmalıdır. Servis yolu genişliği yetersizdir.

Duraklar demir profil çubuklarıyla birbirinden ayrılmış olup, her iki durağa 1 adet otomatik suluk planlanmıştır. Sığırlar duraklara bir zincirle bağlanmaktadır. Durak genişliği $110 \mathrm{~cm}$ 'dir. Olgun (2011)'e göre durak genişliği yeterlidir.

Ahırdaki geçit yolları iki taraflı olarak düzenlenmiş olup, 1 adet $135 \mathrm{~cm}, 1$ adet $145 \mathrm{~cm}, 2$ adet 165 $\mathrm{cm}, 2$ adet $165 \mathrm{~cm}, 10$ adet de $170 \mathrm{~cm}$ genişliğine sahip her bölmede 2 adet olmak üzere toplam 16 adet geçit yolu bulunmaktadır. Ekmekyapar (1981), bu değerin 80-110 cm arasında ortalama $90 \mathrm{~cm}$ olması gerektiğini belirtmiştir. Geçit yollarının tamamının genişlik değerleri gereğinden çok fazladır.

Ahırın güney cephesinde her bölmede bir adet olmak üzere $170 \mathrm{~cm}$ genişliğinde $220 \mathrm{~cm}$ yüksekliğinde 8 adet kapı ve tamamı güney yönde olan $280 \mathrm{~cm}$ genişliğinde ve $80 \mathrm{~cm}$ yüksekliğinde tek camlı 16 adet pencere bulunmaktadır. Pencere alanının ahır taban alanına oranı \%2,86 olup bu değer yetersizdir. Ekmekyapar (1999)'a göre bu değer \%3,5 olmalıdır. Balaban ve Şen (1988) kapı genişliklerinin 100$125 \mathrm{~cm}$, yüksekliklerinin de $200 \mathrm{~cm}$ olmasını, $225 \mathrm{~cm}$ 'den yüksek kapıların önerilmediğini belirtmektedirler. Bu kıstasa göre kapı genişlikleri ve yükseklikleri gereğinden fazladır.

Ahırda taban betondan yapılmış olup, tavan yoktur. Taban ile çatı alt kirişi arasındaki yükseklik 230 cm'dir. Alkan (1973) soğuk bölgelerde ahır yüksekliğinin $225-275 \mathrm{~cm}$ arasında olabileceğini belirtmiştir. Ahır yüksekliği uygundur. Ahırın güney tarafında 7 adet de $380 \times 380 \mathrm{~cm}$ boyutlarında gübre çukuru bulunmaktadır.

Besi sığıı yetiştiriciliğinde kullanılan 50 sığır kapasiteli ahırın uzun cepheleri doğu ve batı yönlerine bacak şekilde planlanmıştır. Ahırın genişliği $10,05 \mathrm{~m}$ uzunluğu $6,45 \mathrm{~m}$ ve yüksekliği $3,20 \mathrm{~m}$ dir. Ahırın kuzey cephesinde ve ahıra bitişik olan süt odasının genişliği $380 \mathrm{~cm}$ 'dir. Ahır süt sığırı ahırı olarak planlanmış olup besi amaçlı olarak kullanılmaktadır. Ahır genişliği iki sıralı ahırlar için Balaban ve Şen (1988)'e göre uygundur. Ahırın yüksekliği Alkan (1973)'ın soğuk bölgeler için belirtmiş olduğu $225-275 \mathrm{~cm}$ 'lik ahır yüksekliği değerine uygunluk göstermemektedir. Ahırda uzun tip durak planlanmış olup, yemlik yolu genişliği $90 \mathrm{~cm}$, yemlik genişliği $75 \mathrm{~cm}$, dikilme platformu uzunluğu 200 $\mathrm{cm}$, idrar kanalı genişliği $25 \mathrm{~cm}$ ve servis yolu genişliği $125 \mathrm{~cm}$ 'dir. Yemlik derinliği yemlik yolu tarafında $55 \mathrm{~cm}$ diğer tarafta ise $35 \mathrm{~cm}$ 'dir. Temizleme ve yemleme gibi işler insan eliyle yapıldığından yemlik yolu, yemlik ve servis yolu genişlikleri yeterli; dikilme platformu uzunluğu ve yemlik eşik yüksekliği fazla; idrar kanalı genişliği ise yetersizdir. Alkan (1973) soğuk bölgelerde ahır içi işlerinin elle yapılması durumunda yemlik yolu genişliğinin $80-10 \mathrm{~cm}$, yemlik genişliğinin $60-70 \mathrm{~cm}$, dikilme platform uzunluğunun $150-180 \mathrm{~cm}, \mathrm{~cm}$ arasında olmasını önermektedir. İdrar kanalının genişliğinin yetersiz olması nedeniyle temizlik işlerinin kürekle yapılması güçleşmektedir. 
Ahırda geçit yolları ahır güney tarafında $205 \mathrm{~cm}$, kuzey tarafında ise $220 \mathrm{~cm}$ 'dir. Bu durumda geçit yolu genişlikleri gerekli olan genişliklerden fazla bırakılmıştır. Ekmekyapar (1999) geçit yolları için 80-110 cm arasındaki değerlerin yeterli olacağını belirtmiştir. Geçit yolları genişliği gereğinden fazla planlanmışırı.

Ahırın doğu ve batı yönlerinde 4'er adet pencere bulunmaktadır. Doğu yönündeki pencerelerin genişliği $197 \mathrm{~cm}$ batı yönündekilerin ise $207 \mathrm{~cm}$ 'dir. Pencere yükseklikleri $75 \mathrm{~cm}$, pencerelerin tabandan yükseklikleri $130 \mathrm{~cm}$ 'dir. Toplam pencere alanının taban alanına oranı $\% 3,7$ olup, bu değer gereğinden fazladır. Ekmekyapar (1999) bu değerin soğuk bölgelerde \%35 olması gerektiğini belirtmiştir.

Ahırda $195 \times 210 \mathrm{~cm}, 200 \times 210 \mathrm{~cm}$ 100x200 cm boyutlarında 3 adet kap1 yer almaktadır. Kap1 yüksekliklerinin uygun olmasına karşın, batı ve güney yönlerindeki kapıların genişlikleri fazladır. Nitekim Balaban ve Şen (1988) tek kanatlı kapı genişliklerinin 100-125 cm, çift kanatlıların ise 150$165 \mathrm{~cm}$ arasında olmasının uygun olduğunu, kapı yüksekliklerinin de $225 \mathrm{~cm}$ 'yi geçmemesi gerektiğini belirtmişlerdir. Ahırda özel bölme planlanmamıştır.

Araştırma alanında uzun cepheleri güney ve kuzeye bakacak şekilde düzenlenmiş: dış boyutları 1160 $\mathrm{cm}$ x $3590 \mathrm{~cm}$ olan yumurta üretimine yönelik kafes tavukçuluğu yapılan 2003 y1lında 6250 hibrit türü tavuk barındırılan bir kümes planlanmıştır. Kümesin çatısı eşlenik beşik çatı şeklindedir. Kümesin girişi doğu cephesindeki kapıdan yapılmaktadır. Kapının genişliği $160 \mathrm{~cm}$, yüksekliği 220 cm'dir.

Kümeste kafesler 4 sıra düzenlenmiș olup her sırada 3 katlı çift taraflı kafesler yer almaktadır. Kafes katlarının toplam yüksekliği $205 \mathrm{~cm}$, kafes sıra genişliği $140 \mathrm{~cm}$ olup, kafes bölme ölçüleri derinlik 45 $\mathrm{cm}$, genişlik $47,5 \mathrm{~cm}$, ön yükseklik $45 \mathrm{~cm}$, arka yükseklik $37,5 \mathrm{~cm}$ 'dir ve her bölmede 5 tavuk barındırılmaktadır. Bu değerler Ekmekyapar (1999)'ın önerdiği değerlere uygundur.

Yemlikler, kümesin uzun duvarlarına paralel olacak şekilde kafeslerin üzerine yerleştirilmiş olup, her kafes bölmesinde de bir adet damlalıklı (nipel) suluk yer almaktadır. Kümeste kafes sıralan arasında $95 \mathrm{~cm}$ genişliğinde kafesler ile uzun duvarlar arasında 115 ve $125 \mathrm{~cm}$ genişliğinde servis yolları bırakılmıştır. Kafes sıralarının kısa duvarlara uzaklıkları 230 cm'dir (Şişman ve Okuroğlu 1981), iki veya daha çok sıralı kafes sisteminde kafes sıraları arasında ve kafesler ile uzun duvarla arasında 90$120 \mathrm{~cm}$ genişliğinde servis yolu bırakılmasını önermişlerdir. Kafes sıralarının kısa duvarlara uzaklıklarının en az $150 \mathrm{~cm}$ olması gerektiğini belirtmişlerdir. Bu değerlendirmeye göre servis yolu genişlikleri uygundur ancak yalnızca güney cephe tarafında bırakılan servis yolunun genişliği $125 \mathrm{~cm}$ olup gereğinden fazla bırakılmıştır.

Tavukların gübreleri kafesler arasındaki boşluklara yerleştirilmiş olan $85 \mathrm{~cm}$ genişliğindeki gübre bandı ile gübre çukuruna dökülmektedir.

Kümeste yumurta odası planlanmamıș, bir adet bakıcı odası planlanmıștır. Bakıcı odasının iç boyutları $380 \times 450 \mathrm{~cm}$ olup, odada 120x120 cm'lik bir pencere bulunmaktadır. Bakıcı odasının kapısı 100x 205 cm boyutlarındadır.

Kümesin yan duvar yüksekliği 315 cm'dir. Alkan (1969) soğuk bölgeler için bu değerin 250- $275 \mathrm{~cm}$ olacağını belirtmiştir.

Şişman ve Okuroğlu (1981), kümeste kapı genişliklerinin 75- $110 \mathrm{~cm}$, yüksekliklerinin ise $200 \mathrm{~cm}$ olmasını ve kapıların dışa doğru açılmasını gerektiğini belirtmişlerdir. Kümes giriş kapısı $160 \mathrm{~cm}$ genişliğinde ve $220 \mathrm{~cm}$ yüksekliğinde olup, gereğinden fazla geniş ve yüksek yapılmışır. Bakıcı odası ve yem odası kapılarının genişlikleri $100 \mathrm{~cm}$. yükseklikleri ise $205 \mathrm{~cm}$ olup, genişlikleri uygun yükseklikleri gereğinden fazladır. Yem odasının kapı genişliği $100 \mathrm{~cm}$, yüksekliği $205 \mathrm{~cm}$ olup kapı metalden yapılmıştır. Kümeste kafeslerin bulunduğu kısım için güney yönünde 5 adet 170 x120 cm boyutunda, kuzey yönünde ise 5 adet $90 \times 75 \mathrm{~cm}$ boyutunda pencere yer almaktadır. Pencerelerin dış yüzeylerine tel örgü çekilmiştir. Pencere toplam alanı $13,575 \mathrm{~m}^{2}$ olup, faydalı taban alanına oranı \%3,98'dir. Ekmekyapar (1999) tavuk kümeslerinde pencere alanının kümes taban alanına oranının soğuk bölgelerde $\% 5$, 1lık bölgelerde $\% 10-15$ ve sıcak bölgelerde \%20-30 olabileceğini belirtmiștir. Cephelerde düzenlenen pencereler doğal aydınlatma için yetersizdir. Kuzey cephe duvarlarında 4 adet daire kesitli $65 \mathrm{~cm}$ çapında fan, 4 adet de $350 \mathrm{~cm}$ uzunluğunda $20 \mathrm{~cm}$ yüksekliğinde havalandırma giriş açıklığı planlanmıștır. Kümesin güney cephesinde ise 4 adet havalandırma giriş açıklığı düzenlenmiştir. Ayrıca kümes yapımı bittikten sonra kümes mahyasında 4 adet daha havalandırma 
çıkıș açıklığı yapılmıștır. Kümeste yem odasında bir adet $115 \times 75 \mathrm{~cm}$ boyutunda, bakıcı odasında ise bir adet $120 \times 120 \mathrm{~cm}$ boyutunda pencere yer almaktadır.

\section{SONUÇ VE ÖNERILER}

Barınaklar genel olarak hayvanlar için uygun planlama kriterlerini taşımalarına karşın, barınaklarda bazı yapı elemanlarının boyutları istenen değerlerden daha küçük bazıları ise gereğinden büyük planlanmıştır. Daha verimli ve karlı hayvancılık faaliyeti, hayvan barınaklarının fiziksel koşullarının istenen özellikleri taşıyabilmesi için belirlenen eksikliklerin giderilmesi, barınak yapı elemanlarının gereğinden fazla boyutlarda yapılmasının önüne geçilmesi yoluyla hem sağlık açısından, hem de barınak maliyetlerinin ekonomik düzeyde kalmasıyla gerçekleştirilebilecektir.

\section{TEŞEKKÜR}

Bu çalışma "Atatürk Üniversitesi Ziraat Fakültesi Ziraat İşletme ve Döner Sermaye Müdürlüğü Uygulama Çiftliğinin Kültürteknik Yönünden Sorunlarının Belirlenmesi Üzerine Bir Araştırma" isimli yüksek lisans tezinden üretilmiştir.

\section{KAYNAKLAR}

Alkan, Z., 1969. Tavuk Kümeslerinin Planlanması. Atatürk Üniversitesi Ziraat Fakültesi Yayınları No: 18, Erzurum.

Alkan, Z., 1973. Ahır Planlanmasının Teknik Esasları. Atatürk Üniversitesi Ziraat Fakültesi Yayınlan No: 189, Erzurum.

Anonim, 1978. Housing Of Beef Cattle, Ministry Oof Agricultural, Fisheries and Food, leaflet 50, Her Majesty's Stationery Office, London.

Balaban, A., Şen. E., 1988. Tarımsal Yapılar. Ankara Üniversitesi Ziraat Fakültesi Yayınları No: 1083. Ankara.

Ekmekyapar, T., 1981. Tarımsal İnşaa Ders Notları, Atatürk Üniversitesi Ziraat Fakültesi, tarımsal Yapılar ve Sulama Bölümü, Erzurum.

Ekmekyapar, T., 1999. Tarımsal Yapılar. Atatürk Üniversitesi Ziraat Fakültesi Ders yayınları No: 204, Erzurum.

Heinrichs, A.J. , Graves, R.E., Kierman, N.E., 1987. Survey of Calf and Heifer Housing on Pennsylvania dairy Farms, Journal of Dairy Science, 70(9):1952-1957.

Okuroğlu, M., 1988. Erzurum İli Merkez İlçede Kamu Kuruluşları Desteği ile Yapılan süt Sığııı Ahırlarının Yapısal Durumu ve Geliştirme Olanakları Üzerine bir Araştırma. Atatürk Üniversitesi Ziraat Fakültesi Dergisi 25(4): 579-598, Erzurum.

Okuroğlu, M., Yağanoğlu, A.V., 1993. Kültürteknik. Atatürk Üniversitesi Ziraat Fakültesi Yayınları, No: 157, Erzurum

Olgun, M., 2011. Tarımsal Yapılar (II. Baskı). Ankara Üniversitesi Ziraat Fakültesi Yayın No: 1577, Ders Kitabı :529, Ankara.

Şişman, N., Okuroğlu, M., 1981. Kafes Tavukçuluğu Kümesleri, Kafesler ve Ekipmanlar. Atatürk Üniversitesi Ziraat Fakültesi Dergisi, 13 (1-2): 99-115, 1982, Erzurum. 